\title{
GEOSPATIAL ASSESSMENT OF HUMAN-WILDLIFE-ENVIRONMENT INTERACTIONS FOR SPATIAL DECISION SUPPORT
}

\author{
M. Madden ${ }^{1 *}$, M. Karidozo ${ }^{2}$, W. Langbauer ${ }^{2}$, F. Osborn ${ }^{2}$, A. Presotto ${ }^{3}$, R. Parry ${ }^{4}$ \\ ${ }^{1}$ Center for Geospatial Research, Dept. of Geography, University of Georgia, Athens, Georgia, USA - mmadden@uga.edu \\ ${ }^{2}$ Connected Conservation, Victoria Falls, Zimbabwe - (mkmalvern, loki.osborn, bill.langbauer)@gmail.com \\ ${ }^{3}$ Dept. of Geography and Geosciences, University of Salisbury, Salisbury, Maryland, USA - axpresotto@salisbury.edu \\ ${ }^{4}$ Victoria Falls Wildlife Trust, Victoria Falls, Zimbabwe - roger@vicfallswildlifetrust.org
}

Commission IV, WG IV/6

KEY WORDS: Spatial Decision Support, High Resolution Imagery, Animal Movement Data, Mitigation, Human-Elephant Conflict

\begin{abstract}
:
Human-Elephant Conflict (HEC) is a global concern that requires geospatial data collection, analysis and geovisualization for decision support and mitigation. Bull African elephants, (Loxodonata africana), are often responsible for breaking fences, raiding crops and causing economic hardship in local communities in Botswana, Zimbabwe and Zambia. Methods for monitoring and understanding elephant movements are needed to mitigate conflict, find ways for coexistence and secure the future of Africa's elephant populations. Researchers from academia and conservation organizations are partnering with decision makers and scientists of the Zimbabwe Department of National Park and Wild Life Management (PWMA) to track the movement of 15 bull elephants in the general area of Victoria Falls to analyse spatio-temporal patterns of elephant behaviour related to climatic factors, habitat conditions and changing land uses. Spatial decision support for local famers, resource managers and planners will assist in avoiding agricultural expansion and urban development that coincides with elephant corridors and access to water resources.
\end{abstract}

\section{INTRODUCTION}

Elephants are considered the major driver for wildlife conflict and biodiversity changes in African ecosystems where they persist. Seventy-five percent of Africa's bush elephants (Loxodonata africana) now live in the Kavango-Zambezi Transfrontier Conservation Area (KAZA-TFCA) in southern Africa, along with three million people. Finding ways to coexist with the elephants is essential to secure the future of Africa's elephants and improve the futures of the people of the region (Hoare and du Toit, 1999; Hoare 2000). Elephant bulls are the primary raiders of crops in this region. This damage annually causes economic hardship and risk to food security in the region, as well as harming local opinion towards conservation in general, and elephants in particular (Gillinghan and Lee, 2003; Kansky et al., 2014). The long-term goal of this research is to assist decision makers such as resource managers and scientists of the Zimbabwe Department of National Park and Wild Life Management (PWMA) and policy makers of Victoria Falls, Zimbabwe by partnering with wildlife and geospatial scientists. Geospatial data and analyses are being used to assess humanwildlife-environment interactions towards human-elephant coexistence in a multi-use landscape (Graham et al., 2009; Songhurst et al., 2016). The integration of image data and conflict occurrences with elephant movement data before and after mitigation measures provides useful information to decision makers. This study will benefit wildlife scientists, resource managers and development planners not only in Zimbabwe, but may serve as a model for other areas of abundant elephant populations throughout Africa.

Elephants are responsible for the vast majority of crop damage by wildlife in Zimbabwe and the other countries that make up the KAZA-TFCA (Karidozo et al., 2016). In Zimbabwe, there are about 40 instances per ward of elephant crop raiding reported each growing season. Numerous studies across Africa and Asia confirm that most crop-raiding elephants are bulls, from the same age classes as those observed threatening local community members and tourists to destinations such as Victoria Falls. We are integrating vegetation and land use/land cover data derived from time-series satellite imagery of high spatial resolution with elephant movement data and reports of human-elephant conflict to assess spatio-temporal patterns of bull elephant behaviour related to environmental factors and human activities (Presotto et al., 2019).

\section{GEOSPATIAL ANALYSIS SUPPORTS MITIGATION}

This study uses a time-series of satellite imagery (Landsat, Sentinel-2, Planet) to produce detailed vegetation and land use/land cover databases of Victoria Falls and surrounding tribal communal lands to map the growth of development and agricultural expansion (Madden et al., 2009). The tracks of 14 bull elephants wearing GPS collars since 2017 are analyzed to determine spatio-temporal patterns of behaviour during wet and dry seasons relative to changing land uses and habitat condition. Various spectral indices such as normalized difference vegetation index (NDVI), enhanced vegetation index (EVI) and soil adjusted vegetation index (SAVI) are derived to assess elephant habitat quality related to bull movements and crop cycles.

Resource managers use a variety of mitigation measures to prevent crop destruction by elephants (Karidozo and Osborn, 2005; King, et al., 2011; Kiffner et al., 2020). One objective of this study is to provide local farmers with information on the efficacy of elephant mitigation techniques including the use of resin from chilli peppers (Capsicum spp.) in elephant-repellent systems. Capsium oleoresin contains capsaicin, a chemical that 
produces a burning sensation that has been used to repel problem animals such as bears and elephants (Hunt, 1985; Osborn and Rasmussen, 1995; Osborn, 2002). We aim to use geospatial analyses of problem bull elephant movements before and after chilli pepper mitigation to assess the effectiveness of different methods of application (e.g., oil in aerosols inhaled by elephants vs. concentrated chilli mash rubbed on elephants immobolized by darting). We also hope to build the capacity of PWMA resource managers and members of the local community so they will be better able to use, maintain and augment the geospatial databases we create (Bernardes, et al., 2020).

Scientists from Connected Conservation are working with local farmers to grow chilli peppers from which they make oils and mash for wildlife conflict mitigation (Karidozo and Osborn, 2015) (Figure 1). Training sessions are held to teach methods for extracting chilli oil and infusing ping pong balls to be used in potato launchers to drive away raiding elephants (Figure 2).
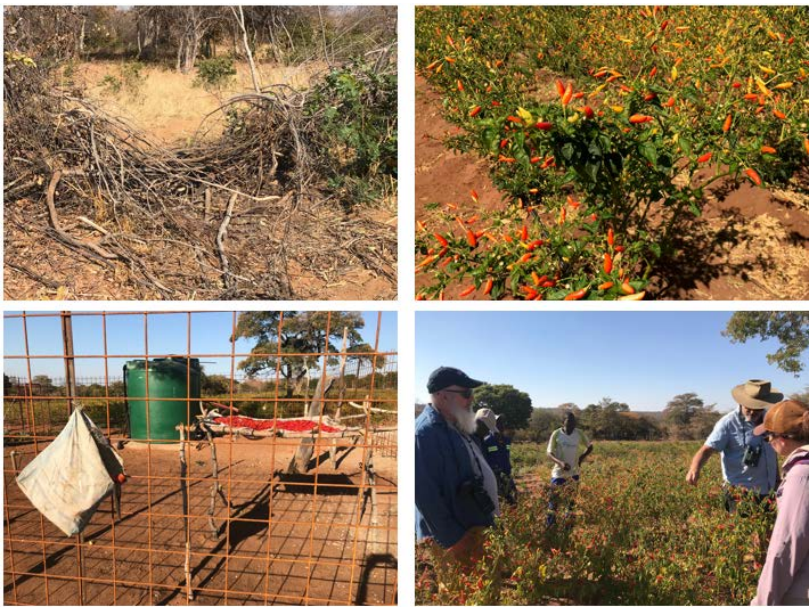

Figure 1. To mitigate elephants raiding local crops, farmer plant chilli peppers used to extract capsium oleoresin oils and make a mash that is rubbed on darted elephants.

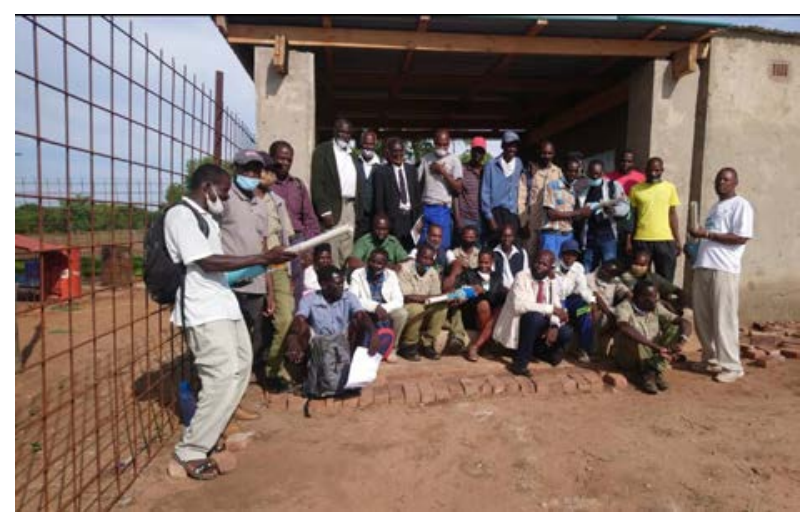

Figure 2. Training local farmers on the use of chilli oil infused ping pong balls and potato launchers to drive away raiding elephants.

One problem bull elephant, for example, was found harassing local school children at the Baobab Primary School in Victoria Falls, Zimbabwe on July 20, 2018. He had been previously collared with a GPS unit in 2017 and was designated problem Bull 2 because he spent considerable time in and around Victoria Falls, often seen walking down the Main Street of town and feeding on trees and bushes near hotels and tourist attractions such as Victoria Falls. Noting the problem bull at the
Baobab School was wearing a GPS collar, the National Park rangers notified our research group and they responded immediately to dart the bull and smear him with chilli-infused wax. Upon awakening, Bull 2 moved away from the school towards the Zambezi River, meandered through Victoria Falls on day 2 and then left town on day 3 (Figure 3). Since July 22, 2018, the GPS-collared bull has returned to Victoria Falls many times, but he has never ventured within 500-m of the site of the chili-wax mitigation.

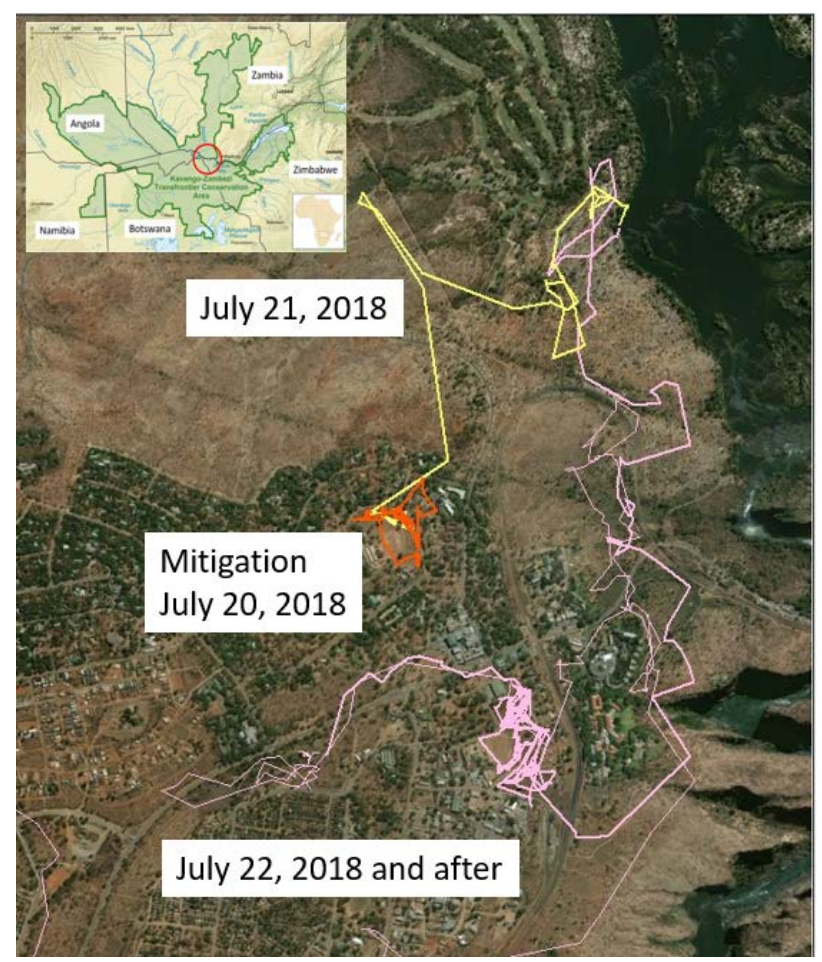

Figure 3. GPS tracks of a bull elephant in Victoria Falls show the behaviour of Bull 2 immediately following chili mitigation measures to prevent future human-elephant conflict.

\section{DECISION SUPPORT FOR ELEPHANT CONFLICT AT THE VICTORIA FALLS INTERNATIONAL AIRPORT}

Based on the movement behaviour of Bull 2 following chilli mitigation in 2018, and his avoidance of the site of darting and chilli mash application at the Baobab Primary School for over two years, a coalition of NGOs cooperated with PWMA park resource managers and local stakeholders to respond to a recent and on-going human-elephant conflict. In mid-February, 2021, a young large bull broke through a fence at the Victoria Falls International Airport and repeatedly went to the runway area to eat wild melons ripening in a field adjacent to the airport's only runway. The Airports Company of Zimbabwe and the Civil Aviation Authority of Zimbabwe notified the PWMA resource managers and although one solution involved shooting the problem animal endangering airport safety, the group of NGOs was given permission to first attempt mitigation with chilli. After many nights of surveillance and attempts to dart the problem bull feeding in the runway area, a team from Connected Conservation, Victoria Falls Wildlife Trust and Hunters Africa were able to dart the bull and deploy GPS collar \#15 (Brown, 2021). While immobilized, chilli mash was applied to the bull's trunk and mouth areas (Figure 4). Upon reversal of the tranquilizer, Bull 15 stood up and immediately ran away from the airport area. 


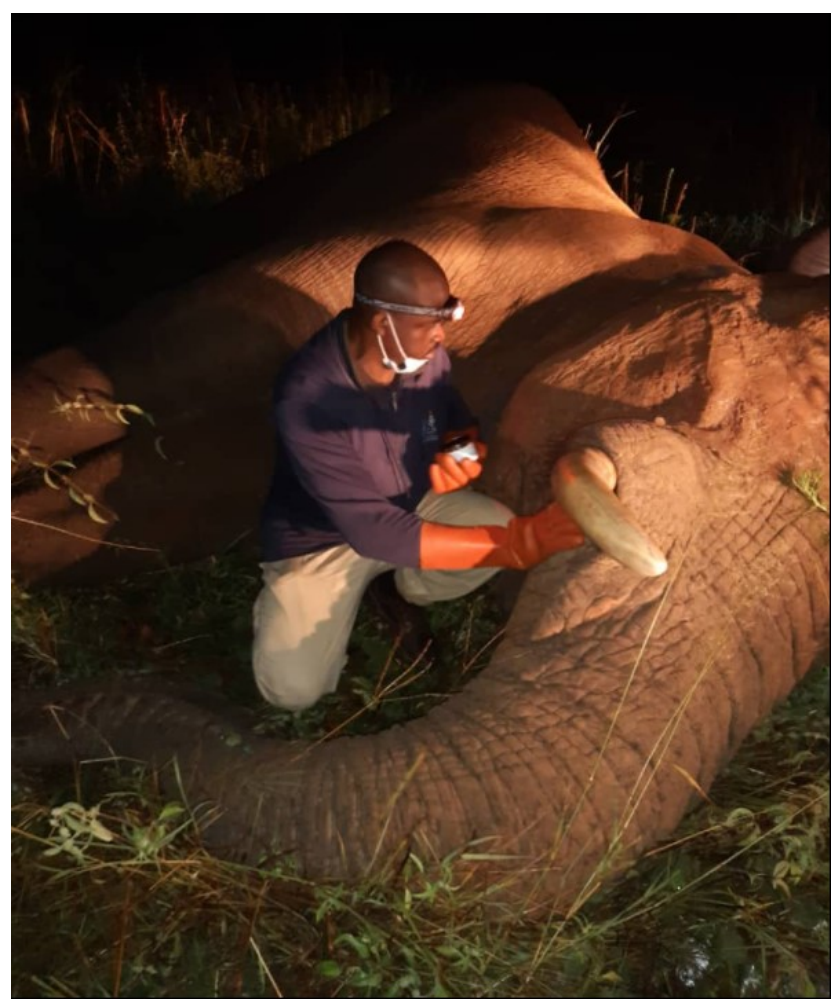

Figure 4. Malvern Karidozo applies chilli mash to Bull 15 after the bull elephant was darted and a GPS collar was deployed.

The movements of Bull 15 are currently being tracked on cell phones using the SKY-Q Mobile App, Google Earth and ArcGIS Pro to display GPS point locations recorded once per hour (Figure 5). In the days following the application of chilli mash in February 2021, Bull 15 was tracked breaking fences and observed raiding crops in the communal lands located northwest of the airport. A display of day and night locations in March indicated Bull 15 remained in natural areas of private lands during the day, continued to break fences and raid crops in the communal lands during the night (Figure 6). Although he did not return to the location of his original darting and application of chilli mash at the airport, his continual crop raiding continued to designate him as problem animal. In an attempt to save Bull 15 from being shot, there was an additional opportunity to dart him in March and apply chilli mash when he was in the agricultural fields. A 2D animation of Bull 15's hourly locations after the second chilli mash application show the bull approaching the crop lands, but then veering away. Researchers continue to observe his daily tracks and are conducting geospatial analyses to identify hot spots of landscape occupation and corridors of movement to assess the effectiveness of the chilli mitigation in deterring Bull 15 from returning to the crop fields.
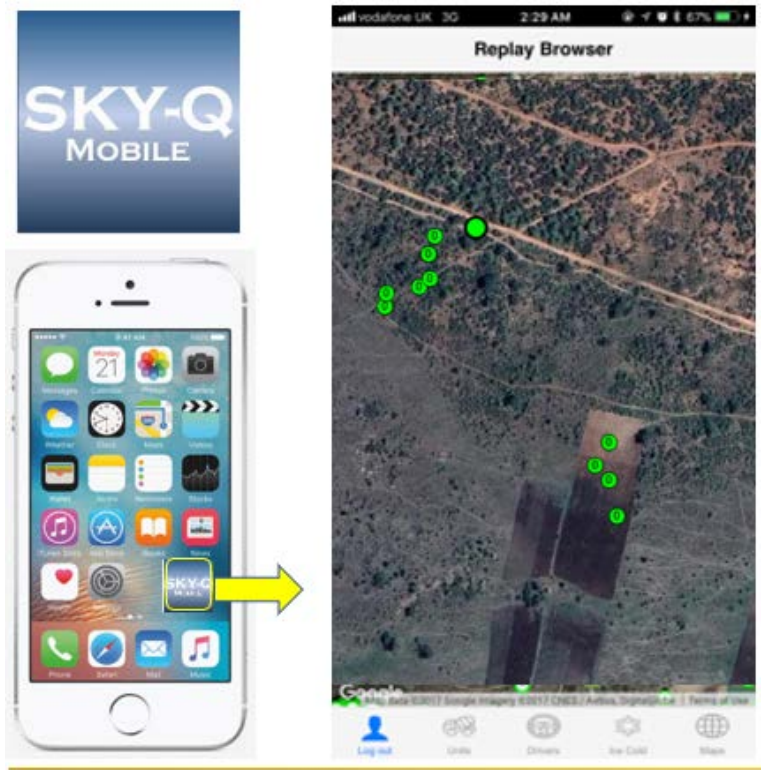

Figure 5. Bull 15 movements and behaviours such as breaking fences and raiding crops in communal lands are monitored on mobile devices.

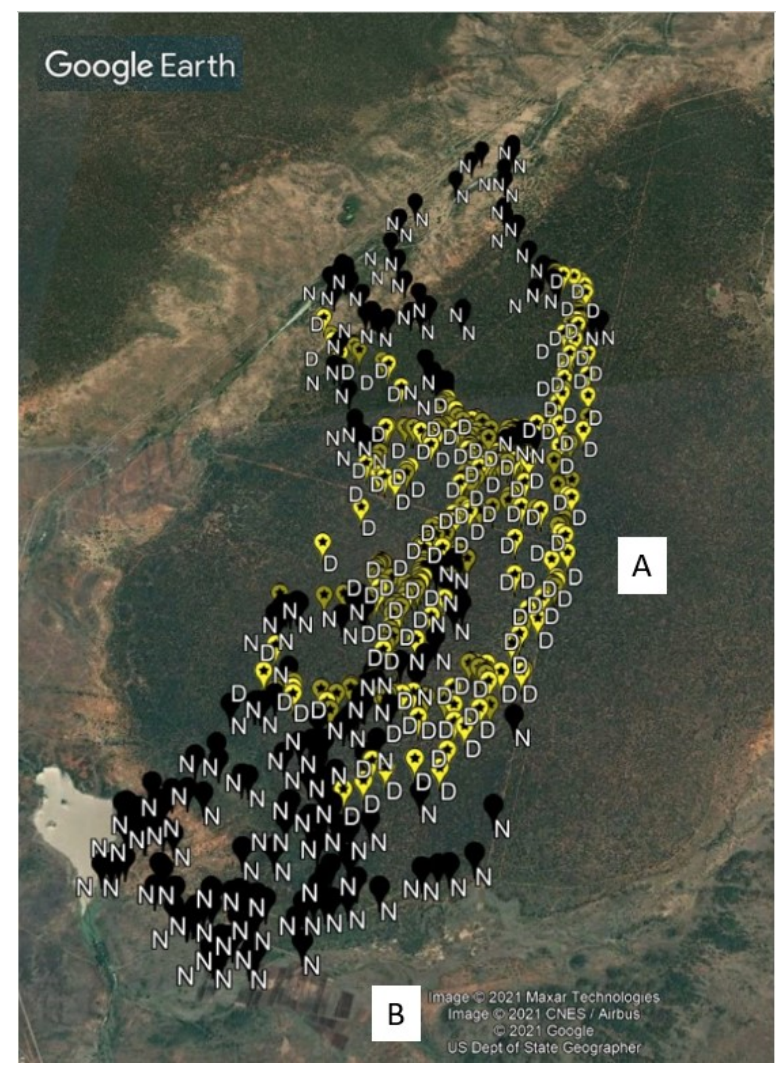

Figure 6. Google Earth provides an accessible platform for displaying Bull 15 movements. Yellow "D” points mark day locations and black "N" points mark night locations. In the month of March, Bull 15 stayed within private lands during the day (A), while at night, Bull 15 broke fences and entered communal lands to raid crops (B).

\section{FUTURE SPATIAL DECISION SUPPORT FOR HUMAN-ELEPHANT CONFLICT}

Maps of bull elephant tracks color-coded by individual elephant or stratified by wet and dry seasons, along with home ranges and hot spots of landscape occupation are assisting wildlife 
scientists and resource managers in understanding differences individual bull behaviour, as well as seasonal patterns of movements of all the collared bull elephants (Figure 7). Animations in 2D are useful for visualizing the relative speed of bull movements in day and night activities. Advanced 3D geovisualizations of individual bull elephant tracks provide further information on the spatio-temporal patterns of elephant movement over time (Figure 8a). With each bull elephant is assigned a distinct color, the breadth of the elephant's movement over the landscape (graphed along the $\mathrm{X}$ and $\mathrm{Y}$ axes) and over time (along the $\mathrm{Z}$ axis) displays the spatio-temporal patterns of movement and behaviour. For example, Bull 3 in green and Bull 9 in purple tend to travel over a wide range of the landscape, while Bulls 1 (yellow) and 4 (blue) exhibit narrow ranges of movements and repetitive patterns of movement. Ground observations confirmed Bull 4 was trapped behind a fence enclosing a private lodge and he often paced back and forth along the fence for weeks before he found his way out of the enclosure

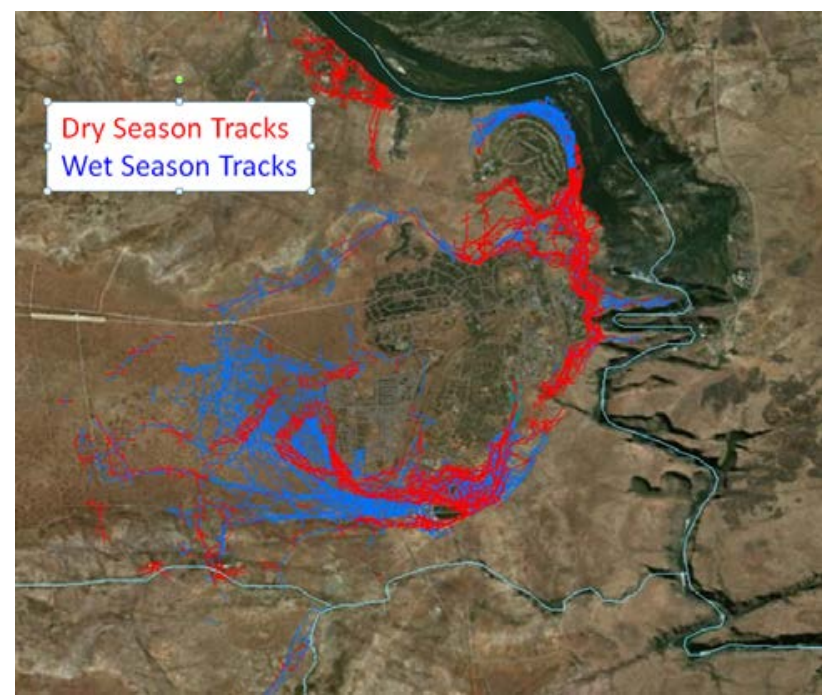

Figure 7. Animated 2D visualizations of bull elephant movements in and around Victoria Falls are color-coded by wet (blue) and dry (red) seasons. The tracks depict differences in locations and dispersion patterns related to habitat condition, food and water availability and the growth of agricultural crops.

Patterns in the tracking data reveal differences in wet-dry season behaviour with elephant distributions being more dispersed in the wet season when elephant habitat condition is high and more concentrated near water sources and human settlements in the dry season. Corridor analyses (Figure 8b) are identifying critical wildlife habitat and patterns of wildlife movement that are needed for landscape planning and development in order to minimize human wildlife conflict (Bastille-Rousseau and Wittemyer, 2020; Salmi et al., 2020). Travel analyses of bull movements are currently underway to locate areas of high elephant use, especially at points of entry to the Zambezi River. Maps of these corridors help local planners to avoid riverside development that will bring elephants in close contact with tourists. A geospatial model of the environmental factors related to risk of crop raiding and other human-conflicts is being incorporated in a spatial decision support system for minimizing conflict and maximizing the potential for human elephant coexistance.

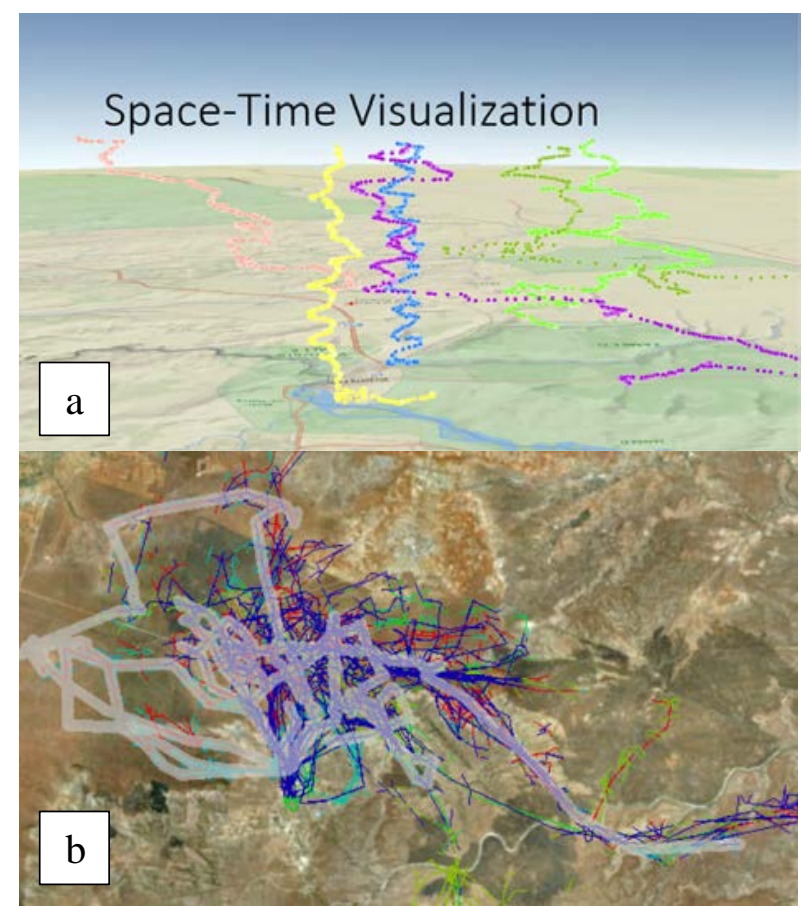

Figure 8. Animated 3D visualizations of color-coded individual bull elephant movements (a) and corridor analysis (b) provide information on the spatio-temporal patterns of elephant behaviour over time.

\section{ACKNOWLEGEMENTS}

Special thanks to Trey Dakota, Salisbury University and Margaret Azami and Kate Markham, University of Georgia for their assistance in geospatial analysis of the bull elephant tracks. We are grateful for support from the Research Council of Zimbabwe; Adrian Read, Managing Director of Hunters Africa; Connected Conservation; and the Victoria Falls Wildlife Trust.

\section{REFERENCES}

Bastille-Rousseau, G., Wittemyer, G., 2020. Characterizing the landscape of movement to identify critical wildlife habitat and corridors. Conservation Biology, DOI: 10.1111/cobi.13519

Bernardes, S., Madden, M. Walker, A., Knight, A., Neel, N., Mendki, A., Bhanderi, D., Guest, A., Healy, S., Jordan, T., 2020. Emerging geospatial technologies in environmental research, education and outreach. Geosfera Indonesia, 5(3), 352-363.

Brown, R., 2021. Elephant inside the airport - Dart and remove operation, Zambesia Newsletter, March 13, 2021.

https://www.zambesia.com/elephant-inside-te-airport-dart-andremove-operation/

Gillingham, S. and Lee, P. C., 2003. People and protected areas: A study of local perceptions of wildlife crop-damage conflict in an area bordering the Selous Game Reserve, Tanzania. Oryx, 37, 316-325.

Graham, M.D., Douglas-Hamilton, I., Adams, W.M., Lee, P.C., 2009. The movement of African elephants in a human-dominated landuse mosaic. Animal Conservation, 12, 445-455.

Hoare, R., 2000. African elephants and humans in conflict: The outlook for co-existence. Oryx, 34, 34-38. 
Hoare, R. E., and du Toit, J. T., 1999. Coexistence between people and elephants in African Savannas. Conservation Biology, 13, 633-639.

Hunt, C.L., 1985. Descriptions of five promising deterrent and repellent products for use with bears. U.S. Fish and Wildlife Service Report 3. Grizzly Bear Recovery Coordinator, Missoula, Montana.

Kansky, R., Kidd, M.,, Knight, A. T., 2014. Meta-analysis of attitudes toward damage-causing mammalian wildlife. Conservation Biology, 28, 924-938.

Karidozo, M., La Grange, M., Osborn, F.V., 2016. Assessment of the human wildlife conflict mitigation measures being implemented by the Kavango-Zambezi Transfrontier Conservation Area (KAZA TFCA) partner countries. Report to the KAZA TFCA Secretariat, Kasane, Botswana.

Karidozo, M. and Osborn, F.V., 2005. Can bees deter elephants from raiding crops? An experiment in the communal lands of Zimabwe. Pachyderm, 39, 26-32.

Karidozo, M. and Osborn, F.V., 2015. Community based conflict mitigation trials: Results of field tests of chilli as an elephant deterrent. Journal of Biodiversity \& Endangered Species, 3(1), 16. DOI: $10.4172 / 2332-2543.1000144$

Kiffner, C., Schaal, I., Cass, L., Peirce, K., Sussman, O., Grueser, A., Washtel, E., Adams, H., Clark, K., Konig, H.J., Kioko, J., 2020. Perceptions and realities of elephant crop raiding and mitigation methods. Conservation Science and Practice, DOI: 10.1111/csp2.372.

King, L.E., Lala, F., Nzumu, H., Mwambingu, E., DouglasHamilton, I., 2011. Beehive fences as effective deterrents for crop-raiding elephants: Field trials in northern Kenya. African Journal of Ecology, 49, 431-439.

Madden, M., Jordan, T., Kim, M., Allen, H., Xu, B., 2009. Integrating remote sensing and GIS: From overlays to GEOBIA and geo-visualization, In, Madden, $\mathrm{M}$. The Manual of Geographic Information Systems, American Society for Photogrammetry and Remote Sensing, Maryland, 701-720.

Osborn, F.V., 2002. Capsicum Oleoresin as an elephant repellent: Field Trials in the Communal Lands of Zimbabwe. The Journal of Wildlife Management, 66(3), 674-677.

Osborn, F.V. and Rasmussen, L.E.L., 1995. Evidence for the effectiveness of an oleo-resin capsicum against wild elephants in Zimbawe. Pachyderm, 20, 15-22.

Presotto, A., Fayrer-Hosken, R., Curry, C., Madden, M., 2019. Spatial mapping shows that some African Elephants use cognitive maps to navigate the core but not the periphery of their home ranges. Animal Cognition, 22(2), 251-263. https://doi.org/10.1007/s10071-019-01242-9

Salmi, R., Presotto, A., Scarry, C., Hawman, P., Doran-Sheehy, D. M., 2020. Spatial cognition in western gorillas (Gorilla gorilla): An analysis of distance, linearity and speed of travel routes. Animal Cognition, 23, 545-557.

https://doi.org/10.1007/s10071-020-01358-3
Songhurst, A., McCulloch, G., Coulson, T., 2016. Finding pathways to human-elephant coexistence: A risky buisness. Oryx, 50(4), 713-720.

https://doi.org/10.1017/S0030605315000344 